\title{
Improved Positive Predictive Performance of Listeria Indicator Broth: A Sensitive Environmental Screening Test to Identify Presumptively Positive Swab Samples
}

\author{
Alan D. Olstein ${ }^{1, *(1)}$ and Joellen M. Feirtag ${ }^{2}$ \\ 1 Paradigm Diagnostics, Inc., 800 Transfer Road Suite 12, St. Paul, MN 55114, USA \\ 2 Department of Food Science and Nutrition, University of Minnesota, St. Paul, MN 55108, USA; \\ jfeirtag@umn.edu \\ * Correspondence: alan.olstein@pdx-inc.com; Tel.: +1-651-295-7768
}

Received: 18 April 2019; Accepted: 25 May 2019; Published: 27 May 2019

check for updates

\begin{abstract}
PDX-LIB, Listeria Indicator Broth, was developed as a proprietary sensitive screening test to identify presumptively positive environmental swab samples for Listeria sp. The original formulation, while sensitive, initially proved to exhibit acceptable levels of false positive test results. Paradigm Diagnostics has been undertaken to modify the medium formulation to render it more selective while not sacrificing its sensitivity. After identification of a candidate formulation through laboratory studies, a field trial was conducted to validate the test performance parameters, including the true positive frequency and false positive frequency in several different food-processing facilities. Identical swab samples were enriched in both the original medium formulation and the new formulation. Presumptive positive samples were confirmed by plating on selective differential agar and qPCR analysis. The field trial data demonstrate that the new formulation significantly reduces the frequency of false positive samples compared to the original Listeria Indicator Broth formulation, without compromising the sensitivity of the original formulation. The new medium formulation resulted in no false positive samples compared to the $54 \%$ increased presumptive positive samples obtained with the original medium formulation.
\end{abstract}

Keywords: food safety; environmental Listeria; Listeria detection

\section{Introduction}

In a risk assessment study, the U.S. Department of Agriculture Food Safety Inspection Service provided the rationale for mandating a national surveillance program for Listeria occurrence in USDA-regulated facilities [1]. These new regulations mandated environmental surveillance for the presence of Listeria sp. in food processing facilities to minimize the risk of foodborne illness associated with contaminated food. This development impelled many firms, including Paradigm Diagnostics, to develop simple Listeria screening tests to enable the growing demand for this test volume [2].

A comprehensive study by the Center for Disease Control in 2012 provided evidence that the implementation of environmental controls in food processing facilities coupled with robust public health monitoring (Pulse Net) helped to reduce the burden of foodborne Listeriosis [3]. Despite these encouraging results, foodborne illnesses due to pathogens, including Salmonella, STEC, and Listeria, continue to be a challenge in the national food production system [4-6]. Figure 1 demonstrates that the frequency of Listeriosis outbreaks in the US has experienced a marked increase in the past few years. Consequently, accurate simple screening methods for foodborne illness pathogens must be available to address the on-going need for facility environmental surveillance. 


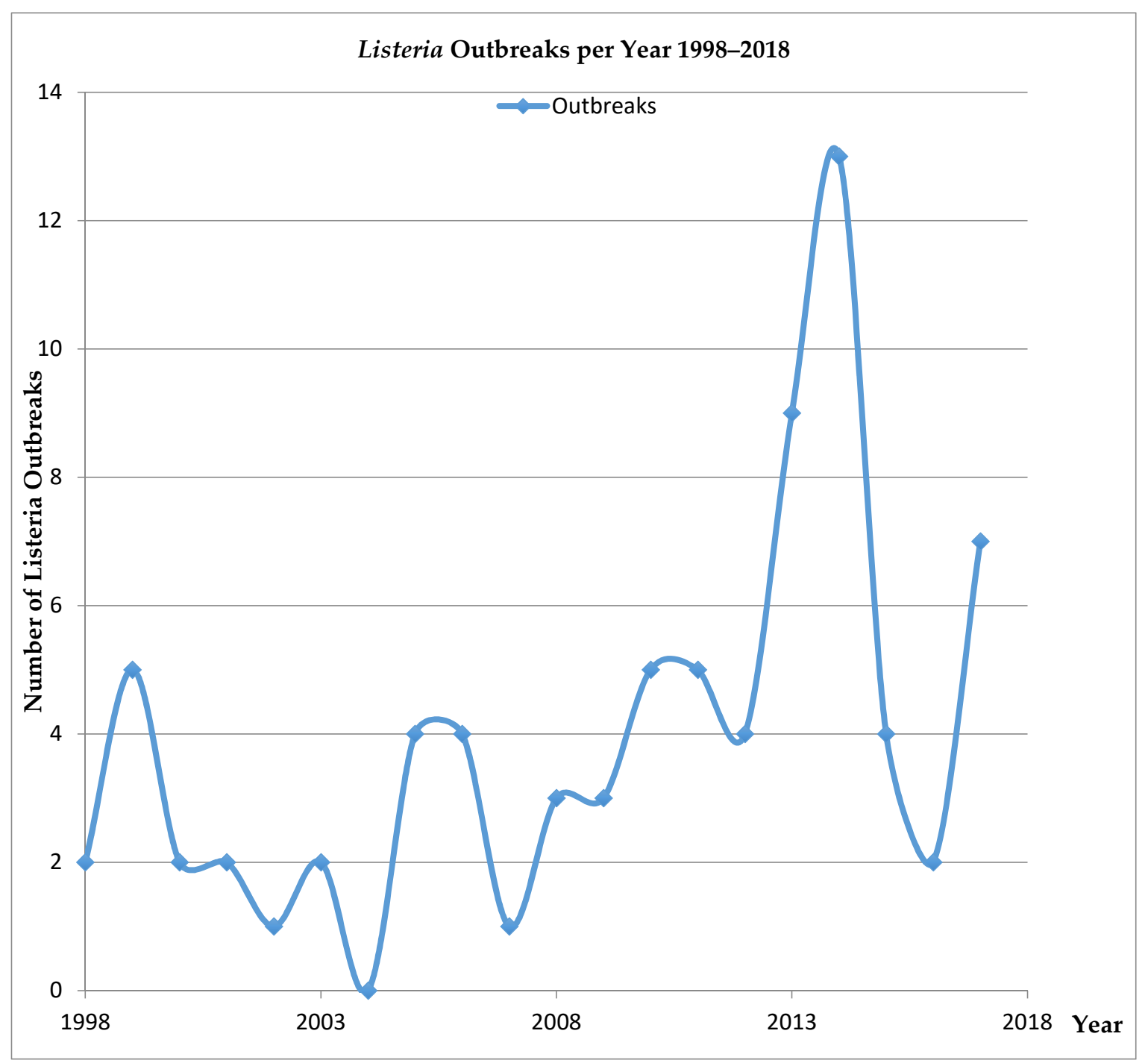

Figure 1. Listeria Outbreaks in the U.S. 1998-2018*. * From the NORS Dashboard Available at https://wwwn.cdc.gov/norsdashboard/. (Accessed on 9 May 2019).

In this study, we intend to demonstrate that an improved Listeria enrichment formulation can help to eliminate uncertainty when screening environmental samples for the presumptive presence of Listeria sp. Field trial data collected from eight different food-processing facilities supports the laboratory data, showing that the new formulation, LIB v.2.0, is more accurate than the antecedent test, LIB. Specifically, the false positives observed using LIB were completely eliminated using LIB v.2.0 without a loss of sensitivity for the detection of true Listeria positive samples. Appendix A was included to provide detailed location information of where the samples were obtained.

\section{Materials and Methods}

PDX-LIB and Listeria Indicator Broth v.2.0 and Securswabs were supplied by Paradigm Diagnostics, Inc. St. Paul, MN. Swabs were collected as duplicates from the same locations in food processing facilities and enriched in $20 \mathrm{~mL}$ of either LIB, the original formulation, or LIB v.2.0, the new medium formulation, for $48 \mathrm{~h}$ at $37^{\circ} \mathrm{C}$. Blackened samples were streaked onto modified MOX (modified Oxford) medium and incubated for an additional $18 \mathrm{~h}$ at $37^{\circ} \mathrm{C}$. The modified MOX medium was prepared by substituting the esculin in the standard MOX formulation with $5 \mathrm{~g} / \mathrm{L} \mathrm{D}$-arabitol and $0.02 \mathrm{~g} / \mathrm{L}$ bromcresol purple as the indicator system for Listeria sp. [7]. 
MOX-positive plates were confirmed as Listeria sp. by qPCR using primers and probes as detailed in the Food and Drug Administration Bacteriological Assay Manual [8]. Statistical analysis was conducted and pairwise comparisons between pathogen isolation rates using LIB v2.0 and LIB (original formulation) were made using the Mantel-Haenszel chi-square formula for unmatched test portions [9]. A Chi-Square value of less than 3.84 was considered to indicate no significant numerical difference between the two methods being compared. The formula for $\chi^{2}$ is

$$
x^{2}=(|a-b|-1)^{2} /(a+b)
$$

$\mathrm{a}=$ The number of presumptively positive samples using LIB v.2.0.

$\mathrm{b}=$ The number of presumptively positive samples using LIB.

\section{Results}

A total of 161 samples were obtained from eight different food-processing facilities. Presumptive positive samples were identified and confirmed. Table 1 summarizes the results of field trial samples. Of the 161 environmental samples, LIB v-2.0 yielded 35 presumptive positives, while the original formulation resulted in 55 blackened samples. The $35 \mathrm{LIB} \mathrm{v-2.0} \mathrm{samples} \mathrm{were} \mathrm{confirmed} \mathrm{as}$ true positives by plating and PCR analysis.

Table 1. Field Trial Summary.

\begin{tabular}{ccccccccc}
\hline Medium & $\begin{array}{c}\text { Total } \\
\text { Samples }\end{array}$ & $\begin{array}{c}\text { Presumptive } \\
\text { Positives }\end{array}$ & Negatives & TP* & TN & FP & FN & X $^{\mathbf{2}}$ \\
\hline LIB & 161 & 54 & 106 & 34 & 106 & 20 & 1 & \\
\hline LIBv-2.0 & 161 & 35 & 126 & 35 & 126 & 0 & 0 & 30.06 \\
\hline
\end{tabular}

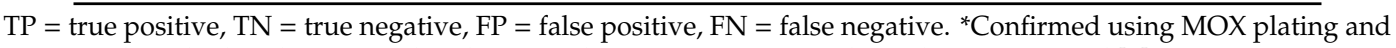
qPCR as described in the US Food and Drug Administration Bacteriological Assay Manual [8].

The LIB (original formulation) results yielded 54 presumptive positives, of which 35 were confirmed. Twenty of the presumptive positive LIB samples were deemed false positives. One hundred and seven of the LIB samples were negative, of which 106 were true negatives. One of the negative LIB samples was deemed a false negative since the duplicate LIB v-2.0 sample yielded a true positive result. Chi square analysis $\left(X^{2}=30.06\right)$ of the positives and false positives generated by both sample populations indicated a significant difference at the $95 \%$ confidence level.

\section{Discussion}

Listeria environmental screening continues to represent a significant proportion of global Listeria testing carried out in the food microbiology laboratory [10]. Accordingly, facile methods to identify presumptively positive environmental samples reduce the cost and time required. Paradigm Diagnostics developed an environmental screening test to identify presumptive positive Listeria samples. The method has been shown to be more sensitive than the USDA method [11] and potentially avoids the risk of false negative samples due to the presence of acriflavin in the enrichment medium used by most commercial enrichment media [12].

The data set in Table 1 represent environmental samples from diverse sources of food-processing facilities, Appendix A. The data translate to a sensitivity and specificity for LIB (original formulation) of $97.2 \%$ and $86.2 \%$, respectively. In contrast, the sensitivity and specificity data for LIB v-2.0 are $100 \%$ and $100 \%$, respectively. The positive predictive values of the respective media are $63 \%$ for LIB and $100 \%$ for LIB v-2.0.

The field data underscore the substantially better diagnostic performance characteristics of LIB v-2.0 compared with the original LIB formulation. Furthermore, the sensitivity of the new medium appears to be comparable to or better than the original formulation. We had anticipated that the 
new formulation would exhibit more false negatives since LIB v-2.0 contains higher levels of lithium chloride than LIB. However, we found that the LIB v-2.0 medium exhibited a greater sensitivity, with a value of $100 \%$ versus $97.2 \%$ for LIB.

This may make sense when one considers that the growth of competitive microflora, particularly Enterococcus sp., may inhibit the growth of Listeria sp. in the sample. In a recent publication, Hanachi et al. detail the potential to use Enterococcus sp., especially E. faecalis and E. faecium, to control the growth of Listeria monocytogenes in food products [13]. In addition to Enterococcus sp., many species within the lactic acid bacteria family are capable of producing anti-listerial compounds. The ability of these organisms to compete with Listeria sp. resides in their capability to both grow more robustly and produce anti-listerial bacteriocins [14].

Appendix A provides detailed site information from which the samples were obtained at their respective facilities.

In conclusion, we have demonstrated that the new formulation of the environmental Listeria screening test, LIB v-2.0, exceeds the performance characteristics of the original formulation, LIB, in comparison field trials. LIB v-2.0 provides a greater accuracy and a higher positive predictive value without sacrificing the test sensitivity.

Author Contributions: J.M.F. developed sampling and field trial citing. A.D.O. developed formulation modifications and implementation.

Funding: This research received no external funding.

Acknowledgments: The authors wish to thank Paradigm Diagnostics, Inc. for donation of materials used to conduct this study.

Conflicts of Interest: A.O. is a Chief Scientific Officer of Paradigm Diagnostics, Inc. Paradigm Diagnostics has provided support for this project through in-kind resources.

\section{Appendix A}

\begin{tabular}{|c|c|c|c|}
\hline \multicolumn{4}{|c|}{ Ready to Eat Food Facility } \\
\hline Location & LIB & LIB v.2.0 & MOX, PCR \\
\hline Cooler 1: Aisle A: Pepper Pallet & NEG & NEG & \\
\hline Squeegee in Cooler 2 & NEG & NEG & \\
\hline Curtain between coolers $1 \& 2$; aisle A & NEG & NEG & \\
\hline Curtain between coolers $2 \& 3$; aisle A & NEG & NEG & \\
\hline Wood under Plate Cooler 2 & NEG & NEG & \\
\hline Dampness behind Wood on floor & POS & NEG & NEG \\
\hline Blue CHEP pallet Cooler 3 (damp) & NEG & NEG & \\
\hline Cooler 3 drain & NEG & NEG & \\
\hline Wood Pallet (damp) Cooler 3 & NEG & NEG & \\
\hline Floor Under Rack (105) wet - cooler 3 & NEG & NEG & \\
\hline ICE from case of Brussel Sprouts Rack 105 Cooler 3 & NEG & NEG & \\
\hline Underneath Table 26; School Cooler & NEG & NEG & \\
\hline Inside of Floor Scrubber lid & POS & NEG & NEG \\
\hline Blue Filter of Floor Scrubber reservoir & NEG & NEG & \\
\hline Inside of Floor Scrubber hose & POS & NEG & NEG \\
\hline Floor Scrubber Brush & NEG & NEG & \\
\hline Dishwasher Floor Drain (Bin cleaning area) & POS & NEG & NEG \\
\hline \multicolumn{4}{|c|}{ Meat Processing_Fermentation/Drying } \\
\hline Location & LIB & LIB v.2.0 & MOX, PCR \\
\hline Drain in packaging room & NEG & NEG & \\
\hline Vacuum Machine & NEG & NEG & \\
\hline Under Packaging Room table & NEG & NEG & \\
\hline Dishwater room drain & POS & NEG & NEG \\
\hline Underneath foot stool & NEG & NEG & \\
\hline Hand sink drain & NEG & NEG & \\
\hline
\end{tabular}




\begin{tabular}{|c|c|c|c|}
\hline \multicolumn{4}{|c|}{ Ready to Eat Food Facility } \\
\hline Squeegee & NEG & NEG & \\
\hline RTE room drain by ECA device & NEG & NEG & \\
\hline Drain in cooked cooler & NEG & NEG & \\
\hline Coving in cooked cooler & NEG & NEG & \\
\hline Smoke cart wheels & POS & NEG & NEG \\
\hline Black cart wheels & NEG & NEG & \\
\hline Dish sink drain right & NEG & NEG & \\
\hline Dish sink drain middle & NEG & NEG & \\
\hline Dish sink drain left & POS & NEG & NEG \\
\hline RTE floor drain outside aging cooler & NEG & NEG & \\
\hline Raw Door Floor & POS & NEG & NEG \\
\hline RTE Food Facility/Sandwiches/Salads & LIB & LIB v.2.0 & MOX, PCR \\
\hline Cooling Unit \# 1 & NEG & NEG & \\
\hline Cooling Unit \#2 & NEG & NEG & \\
\hline Cooling Unit \#3 & NEG & NEG & \\
\hline Cooling Unit \#5 & NEG & NEG & \\
\hline Cooling Unit \#6 & NEG & NEG & \\
\hline Drain \#14 & NEG & NEG & \\
\hline Drain \#15 & POS & POS & Lm \\
\hline Line \#3 Bag hole & NEG & NEG & \\
\hline Threshold Swing Door \#3 & NEG & NEG & \\
\hline Threshold Swing Door \#2 & NEG & NEG & \\
\hline Threshold Swing Door \#1 & NEG & NEG & \\
\hline Above ceiling in Wash Room & NEG & NEG & \\
\hline Threshold H\&C cooler door fr. St & NEG & NEG & \\
\hline Drain \#27 & NEG & NEG & \\
\hline Threshold M\&C cooler door fr. Rec & NEG & NEG & \\
\hline Receiving Threshold & NEG & NEG & \\
\hline Drain \# 9 & NEG & NEG & \\
\hline Threshold shipping cooler Door \#2 & NEG & NEG & \\
\hline Mat in Hallway QA office & NEG & NEG & \\
\hline \multicolumn{4}{|l|}{ Retail Store Food Areas } \\
\hline Deli-Back Room & LIB & LIB 2.0 & MOX, PCR \\
\hline Drain in front of raw chicken sink, inside & POS & POS & Lm \\
\hline Drain in front of 3-compartment sink, inside & NEG & NEG & \\
\hline Drain in back wall underneath racks & NEG & NEG & \\
\hline Inside condenser pipe in-between racks by drain \#7 & POS & NEG & NEG \\
\hline Drain underneath food prep sink & NEG & NEG & \\
\hline Mop sink & NEG & NEG & \\
\hline Drain behind ice machine & NEG & NEG & \\
\hline Top of dishwasher & NEG & NEG & \\
\hline Drain under dishwasher (no cover) & NEG & NEG & \\
\hline Drain in front of Deli cooler & NEG & NEG & \\
\hline Produce Cooler & LIB & LIB v.2.0 & MOX,PCR \\
\hline Inside access port-drain plug-Produce cooler & POS & NEG & NEG \\
\hline Wall in Produce cooler & NEG & NEG & \\
\hline Cooling unit guard inside Produce cooler & NEG & NEG & \\
\hline Frame of shelf in Produce cooler (left side) & NEG & NEG & \\
\hline PRE—by drain in produce cooler - water present & NEG & NEG & \\
\hline PRE—water on floor of produce cooler below box & NEG & NEG & \\
\hline Outside box of produce that was dripping bottom shelf & POS & POS & Lm \\
\hline hole in wall right side middle & NEG & NEG & \\
\hline shelf leg by floor right side & NEG & NEG & \\
\hline shelf leg by door & NEG & NEG & \\
\hline bottom shelf where iced produce sits & NEG & NEG & \\
\hline
\end{tabular}




\begin{tabular}{|c|c|c|c|}
\hline \multicolumn{4}{|c|}{ Ready to Eat Food Facility } \\
\hline middle shelf where iced produce sits & NEG & NEG & \\
\hline shelf where organic produce sits & NEG & NEG & \\
\hline coving on left side by iced produce & NEG & NEG & \\
\hline hole in wall left side by iced produce & NEG & NEG & \\
\hline water on floor where cut fruit sits & NEG & NEG & \\
\hline Deli (Front Room) & LIB & LIB v.2.0 & MOX,PCR \\
\hline Food prep sink drain + underneath cover & NEG & NEG & \\
\hline Drain underneath Combi Oven (cover) & NEG & NEG & \\
\hline Drain under Food Prep Sink & NEG & NEG & \\
\hline Café & LIB & LIB v.2.0 & MOX,PCR \\
\hline Drain under soda fountain & POS & NEG & NEG \\
\hline Drain in front of dishwasher & NEG & NEG & \\
\hline Drain under 3-compartment sink & NEG & NEG & \\
\hline Drain under prep sink & NEG & NEG & \\
\hline Drain by mop sink & NEG & NEG & \\
\hline mop sink & NEG & NEG & \\
\hline Coffee Shop & LIB & LIB v.2.0 & MOX,PCR \\
\hline Drain under sink & NEG & NEG & \\
\hline Foam drain for coffee maker machine & NEG & NEG & \\
\hline Drain under milk/coffee bar & NEG & NEG & \\
\hline \multicolumn{4}{|c|}{ Meat Plant (2) } \\
\hline Location & LIB & LIB v.2.0 & MOX,PCR \\
\hline Meat Rack for snack sticks & NEG & NEG & \\
\hline Drain Oven Room & POS & POS & L. mono \\
\hline Door out of oven room & POS & POS & L. mono \\
\hline Cooler Floor & POS & POS & L. inocua \\
\hline Packaging table & NEG & NEG & \\
\hline RTE tub & NEG & NEG & \\
\hline Snack Stick Cutter & POS & POS & $\begin{array}{c}\text { L. } \\
\text { welshmeri }\end{array}$ \\
\hline \multicolumn{4}{|c|}{ Ready to Eat Food Facility (2) } \\
\hline \multicolumn{4}{|l|}{ Environmental Swabs-pre-op } \\
\hline Location & LIB & LIB v.2.0 & MOX,PCR \\
\hline Drain G cover & NEG & NEG & \\
\hline Line 4 bearing on sprocket shaft & POS & POS & L. inocua \\
\hline Line 4 good bearings & POS & POS & L. mono \\
\hline prep room floor grate & NEG & NEG & \\
\hline floor scrubber & POS & POS & L. mono \\
\hline air hose composite & NEG & NEG & \\
\hline prep room center drain & NEG & NEG & \\
\hline squeegee in production & POS & POS & L. mono \\
\hline squeegee in production & NEG & NEG & \\
\hline squeegee in prep room & POS & POS & Listeria $\mathrm{sp}$ \\
\hline prep room meat and cheese carts & NEG & NEG & \\
\hline Floor under racking & POS & POS & L. mono \\
\hline Floor near prep room wall interface & POS & POS & Listeria $\mathrm{sp}$ \\
\hline Center Floor composite & NEG & NEG & \\
\hline Drain composite N & NEG & NEG & \\
\hline Drain composite $S$ & POS & NEG & negative \\
\hline Fork lift with scale & POS & POS & L. inocua \\
\hline Fork lift (stand up) & NEG & NEG & \\
\hline Cimpl Bologna Pallet & POS & POS & Listeria $\mathrm{sp}$ \\
\hline Cimpl Bologna Cardboard & NEG & NEG & \\
\hline
\end{tabular}




\begin{tabular}{|c|c|c|c|}
\hline \multicolumn{4}{|c|}{ Ready to Eat Food Facility } \\
\hline Cimpl Bologna Plastic & POS & POS & Listeria sp \\
\hline ASE Ham Pallet & POS & NEG & negative \\
\hline ASE Ham Cardboard & POS & NEG & negative \\
\hline ASE Ham Plastic & NEG & NEG & \\
\hline Abbyland Pallet & POS & POS & Listeria $\mathrm{sp}$ \\
\hline Abbyland Cardboard & POS & POS & Listeria sp \\
\hline Abbyland Plastic & NEG & NEG & \\
\hline Hot Ham pallet & POS & NEG & negative \\
\hline Toby 409/AKA T2 & POS & POS & L. mono \\
\hline line 4 bearing (all) & POS & POS & L. mono \\
\hline Line 3 bearing (all) & NEG & NEG & \\
\hline Line 5 bearings (all) & NEG & NEG & \\
\hline \multicolumn{4}{|l|}{ Bakery } \\
\hline Location & LIB & LIB v.2.0 & MOX,PCR \\
\hline Dairy ("Meat") cooler condenser pipe & POS & NEG & negative \\
\hline Dairy ("Meat") cooler drain & POS & POS & L. mono \\
\hline Bakery cooler drain & POS & NEG & negative \\
\hline Bakery cooler condenser pipe & NEG & NEG & \\
\hline Drain in center of bakery room & POS & POS & L. mono \\
\hline Drain at end of bakery cooler & POS & POS & L. mono \\
\hline Long red drain in sandwich prep area & NEG & NEG & \\
\hline Sandwich cooler condenser pipe & POS & POS & L. mono \\
\hline Sandwich cooler drain & POS & NEG & NEG \\
\hline Drain in middle of sandwich prep area & NEG & NEG & \\
\hline "Fast chill" condenser pipe & NEG & NEG & \\
\hline "Fast chill" drain & POS & POS & L. mono \\
\hline Holding cooler condenser pipe & POS & POS & L. mono \\
\hline Holding cooler drain & POS & POS & L. mono \\
\hline Far left "finished product" cooler condenser pipe & NEG & NEG & \\
\hline Far left "finished product" cooler drain & POS & NEG & negative \\
\hline Far right "finished product" cooler condenser pipe & POS & NEG & negative \\
\hline Far right "finished product" cooler drain & POS & NEG & negative \\
\hline Inside tub of floor scrubber & NEG & NEG & \\
\hline Inside of hose out the top of floor scrubber & NEG & NEG & \\
\hline Scrub brush on bottom of floor scrubber & POS & NEG & negative \\
\hline Scrub brush on bottom of floor scrubber & NEG & NEG & \\
\hline Squeegee on back of floor scrubber & NEG & POS & Listeria $\mathrm{sp}$ \\
\hline
\end{tabular}

List of abbreviations: MOX: Modified Oxford Medium, PCR: Polymerase Chain Reaction, PDX-LIB:

Paradigm Diagnostics' Listeria Indicator Broth. Items bold permit easier identification of positive samples in table.

\section{References}

1. Gallagher, D.L.; Ebel, E.D.; Krause, J.R. FSIS Risk Assessment for Listeria monocytogenes in Deli Meats. Available online: https://www.fsis.usda.gov/shared/PDF/Lm_Deli_Risk_Assess_Final_2003.pdf (accessed on 21 December 2018).

2. Olstein, A. Selective Growth Medium for Listeria spp. US Patent 7960164, 14 June 2011.

3. Cartwright, E.J.; Kelly, A.J.; Sharcara, D.J.; Graves, L.M.; Silk, B.E.; Mahon, B.E. Center for Disease Control Listeriosis Outbreaks and Associated Food Vehicles United States, 1998-2008. Emerg. Infect. Dis. 2013, $19,1$. [CrossRef]

4. USDA/FSIS Press Release: JBS Tolleson, Inc. Recalls Beef Products Due to Possible Salmonella Newport Contamination. Available online: https:/www.fsis.usda.gov/wps/portal/fsis/topics/recalls-and-publichealth-alerts/recall-case-archive/archive/2018/recall-085-2018-release (accessed on 21 December 2018).

5. FDA Press Release: The Picsweet Company Recalls 8-ounce Steam'ables Asparagus Spears Due to Potential for Listeria monocytogenes. Available online: https://www.fda.gov/Safety/Recalls/ucm625788.htm (accessed on 21 December 2018). 
6. USDA FSIS Press Release: Swift Beef Company Recalls Ground Beef Products due to Possible E. coli O157:H7 Contamination. Available online: https://www.fsis.usda.gov/wps/portal/fsis/topics/recalls-andpublic-health-alerts/recall-case-archive/archive/2018/recall-114-2018-release (accessed on 21 December 2018).

7. FDA Bacteriological Assay Manual. BAM Media M103a Modified Oxford Listeria Selective Agar. Available online: https://www.fda.gov/downloads/Food/FoodScienceResearch/LaboratoryMethods/ UCM467056.pdf (accessed on 21 December 2018).

8. FDA Bacteriological Assay Manual. BAM Protocol: Simultaneous Confirmation of Listeria species and L. monocytogenes isolates by real-time PCR. Available online: https://www.fda.gov/food/foodscienceresearch/ laboratorymethods/ucm2006949.htm (accessed on 21 December 2018).

9. Mantel, N.; Haensel, W. Statistical Aspects of the Analysis of Data from Retrospective Studies of Disease. J. Nat. Cancer Inst. 1959, 22, 719-748. [PubMed]

10. Ferreira, V.; Wiedmann, M.; Teixeira, P.; Stasiewicz, M.J. Listeria monocytogenes Persistence in Food Associated Environments: Epidemiology, Strain Characteristics, and Implications for Public Health. J. Food Prot. 2014, 77, 150-170. [CrossRef] [PubMed]

11. Olstein, A.; Feirtag, J. PDX-LIB, an Improvement on Selective Enrichment Medium for Environmental Listeria Spp. J. Bacteriol. Parasitol. 2015, 6, 4.

12. Beumer, R.; te Giffel, M.C.; Anthonie, S.V.R.; Cox, L.J. The Effect of Acriflavin and Nalidixic Acid on the Growth of Listeria spp. in Enrichment Media. Food Microbiol. 1996, 13, 137-148. [CrossRef]

13. Hanachi, H.; Mottawea, W.; Sebei, K.; Hammami, R. The Genus Enterococcus: Between Probiotic Potential and Safety Concerns- An Update. Front. Microbiol. 2018, 9, 1791. [CrossRef] [PubMed]

14. Papagianni, M.; Anastasiadou, S. Pediocins: The bacteriocins of Pediococci. Sources, production, properties and applications. Microb. Cell Fact. 2009, 8, 3. [CrossRef]

(C) 2019 by the authors. Licensee MDPI, Basel, Switzerland. This article is an open access article distributed under the terms and conditions of the Creative Commons Attribution (CC BY) license (http://creativecommons.org/licenses/by/4.0/). 